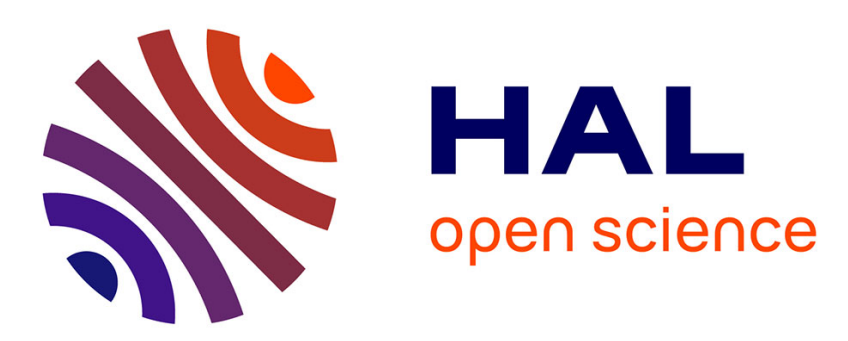

\title{
Integrated static and dynamic modeling of an ionic polymer-metal composite actuator
}

\author{
An-Bang Sun, Damienne Bajon, Jean-Marc Moschetta, Emmanuel Benard, \\ Chinnapat Thipyopas
}

\section{To cite this version:}

An-Bang Sun, Damienne Bajon, Jean-Marc Moschetta, Emmanuel Benard, Chinnapat Thipyopas. Integrated static and dynamic modeling of an ionic polymer-metal composite actuator. Journal of Intelligent Material Systems and Structures, 2014, 10.1177/1045389X14538528 . hal-01006050

\section{HAL Id: hal-01006050 https://hal.science/hal-01006050}

Submitted on 13 Jun 2014

HAL is a multi-disciplinary open access archive for the deposit and dissemination of scientific research documents, whether they are published or not. The documents may come from teaching and research institutions in France or abroad, or from public or private research centers.
L'archive ouverte pluridisciplinaire HAL, est destinée au dépôt et à la diffusion de documents scientifiques de niveau recherche, publiés ou non, émanant des établissements d'enseignement et de recherche français ou étrangers, des laboratoires publics ou privés. 


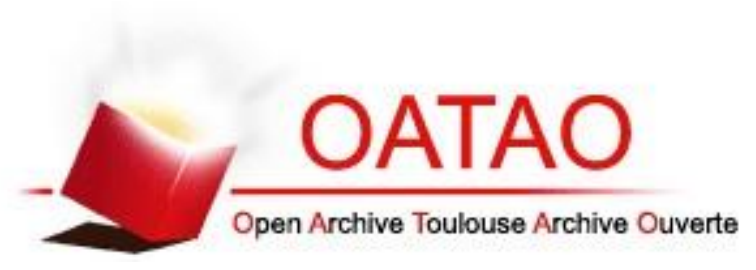

\section{Open Archive Toulouse Archive Ouverte (OATAO)}

OATAO is an open access repository that collects the work of Toulouse researchers and makes it freely available over the web where possible.

This is an author-deposited version published in: http://oatao.univ-toulouse.fr/ Eprints ID: 11751

To link to this article: DOI: $10.1177 / 1045389 X 14538528$

URL: http://dx.doi.org/10.1177/1045389X14538528

To cite this version: Sun, An-Bang and Bajon, Damienne and Moschetta, Jean-Marc and Benard, Emmanuel and Thipyopas, Chinnapat Integrated static and dynamic modeling of an ionic polymer-metal composite actuator. (2014) Journal of Intelligent Material Systems and Structures . ISSN 1045-389X 


\title{
Integrated static and dynamic modeling of an ionic polymer-metal composite actuator
}

\author{
An-Bang Sun ',2, Damienne Bajon', Jean-Marc Moschetta', \\ Emmanuel Benard' and Chinnapat Thipyopas ${ }^{3}$
}

\begin{abstract}
lonic polymer-metal composites have been widely used as actuators for robotic systems. In this article, we investigate and verify the characteristics of ionic polymer-metal composite actuators experimentally and theoretically. Two analytical models are utilized to analyze the performance of ionic polymer-metal composites: a linear irreversible electrodynamical model and a dynamic model. We find that the first model accurately predicts the static characteristics of the ionic polymer-metal composite according to the Onsager equations, while the second model is able to reveal the back relaxation characteristics of the ionic polymer-metal composite. We combine the static and dynamic models of the ionic polymer-metal composite and derive the transfer function for the ionic polymer-metal composite's mechanical response to an electrical signal. A driving signal with a smooth slope and a low frequency is beneficial for the power efficiency.
\end{abstract}

\section{Keywords}

lonic polymer-metal composite, vehicle, experimental exploration, modeling, efficiency

\section{Introduction}

Many "Smart" materials have been proposed to design minimal size, low power consumption, and light-weight robotics. They are classified as materials that can sense changes in their environment (external stimuli such as thermal, magnetic, electrical, chemical, mechanical, or radioactive) and respond in accordance with these changes (Kim et al., 2011b), which include electroactive polymers (EAPs), electroactive ceramics (EACs), shape memory alloys (SMAs), and carbon nanotubes (CNTs). EAPs offer weight and robustness advantages compared to EACs (Bar-Cohen, 2004).

Ionic polymer-metal composites (IPMCs) are a type of EAPs and are made of ion-exchange membrane plated rare metal (normally gold or platinum). When a voltage is applied across the electrode, an electromechanical transduction occurs due to the motion of hydrated cations and water molecules. This leads to a fast bending motion toward the anode, resulting in an actuation effect. Lower driving voltage of IPMCs is compatible with lighter source, also not requiring additional electronic components. In addition, IPMCs have other attractive characteristics compared to SMAs or EACs (Bar-Cohen, 2004; O'Halloran et al., 2008), including miniaturization, lighter weight, lower power consumption, long-life durability, and larger displacement.
These advantages of IPMCs have led to many designs for biomimetic and engineering applications, for example, flapping wings (Colozza, 2007; Kim et al., 2007; Lee et al., 2006), wipers (Bar-Cohen et al., 1999), grippers (Shahinpoor and Kim, 2005), fish-like under-water robots (Aureli et al., 2010; Chen et al., 2010; Najem et al., 2012; Yeom and Oh, 2009; Zhang et al., 2006), microswimmers (Abdelnour et al., 2012), artificial muscles (Kim et al., 2011a; Madden et al., 2004), biomedical devices (Bonomo et al., 2008; Brunetto et al., 2010; Fang et al., 2007; Rodrigues et al., 2011), sensors (Abdulsadda and Tan, 2012; Brunetto et al., 2011; Chen et al., 2013), and mechano-electrical energy harvesters (Aureli et al., 2010; Tiwari and Kim, 2013).

In general, a humid environment is suitable for IPMC actuators, because their bending actuation

\footnotetext{
'Institut Supérieur de l'Aéronautique et de l'Espace (ISAE), University of Toulouse, Toulouse, France

${ }^{2}$ Centrum Wiskunde \& Informatica (CWI), Amsterdam, The Netherlands ${ }^{3}$ Department of Aerospace Engineering, Faculty of Engineering, Kasetsart University, Bangkok, Thailand
}

Corresponding author:

An-Bang Sun, Institut Supérieur de l'Aéronautique et de l'Espace (ISAE), University of Toulouse, ISAE BP 54032 campus SUPAERO 31055

Toulouse cedex 4, Toulouse 31055, France.

Email: absun1984@hotmail.com 
depends on the motion of cations inside the membrane, thus on the hydration level. For the conventional water-based IPMC, evaporation happens at room temperature and the electrolysis starts if the applied voltage is higher than $\sim 1.5 \mathrm{~V}$ (Barramba et al., 2007). This drawback makes the performance of IPMCs in air worse than in water. Much effort has been put to prevent the solvent loss, for example, by replacing the water solvent by ionic liquids (Bennett, 2004; Lee et al., 2011a; Yun et al., 2007), or by encapsulating the IPMC with dielectric gels (Barramba et al., 2007).

The motivation of the current paper is an application of IPMC actuators in controlling the tilt angle of the upper rotor of NAno Coaxial Counter-rotating Rotors (NACCORs) in air (Liu et al., 2010). Nano Aerial Vehicle (NAV) is expected to have a dimension of $7.5 \mathrm{~cm}$, and a total mass of about $10 \mathrm{~g}$ (Darryll, 2005). This strict weight limitation is a major challenge in this project. A prototype of NAV with conventional complex servos is shown in Figure 1(a), and the conceptual design with an IPMC actuator is shown in Figure 1(b). We note that the thin plate format of the IPMC, combined with a high-frequency response, may also be used to design integrated rotor blades. The difficulties of low output force of the IPMC can be solved, for instance with multiple samples. Before assembling the IPMC actuator into the real NACCOR system, the performance and properties of IPMC actuators need to be studied and verified, which is the main objective of this study.

We conduct experiments to investigate the performance of IPMC actuators, and we measure both their mechanical properties (bending displacement, generative force with and without external loading, and stiffness) and their electrical properties (resistance and capacitance). In addition, we focus on identifying and validating the parameters of two representative "gray-box" models. The IPMC samples were purchased from ERI, USA. The base ion membrane is Nafion, with platinum electrodes. The type of mobile ions inside the membrane is sodium, with water as a solvent. The dimension of the sample is $40 \mathrm{~mm} \times 10 \mathrm{nbsp} ; \mathrm{mm} \times 0.3 \mathrm{~mm}$ (length $\times$ width $\times$ thickness), with a gross weight about $0.2 \mathrm{~g}$.

This article is organized as follows. The basic characteristics of the IPMC are initially studied experimentally, following by an assessment of the electromechanical response. The coefficients of the Onsager equations and the transfer function are then derived. These coefficients are then used into two models that describe the static and time-variant dynamic characteristics of the IPMC actuator. Finally, the power efficiency by different driving signals is compared, based on the dynamic model.

\section{Experimental exploration}

\section{Experimental setup}

We measure the bending displacement with a laser displacement meter (model OWLG 4003 AA/AE S2 from AXOM, France), with a typical resolution of $5 \mu \mathrm{m}$. Its measurement range is $10 \mathrm{~mm}$ and the sampling frequency is $1100 \mathrm{~Hz}$. As shown in Figure 2, the IPMC strip works in cantilever configuration. The laser meter is placed so that the laser beam is incident and reflected on a certain measured position of the IPMC strip. One tip of the IPMC strip is fixed by a plastic clamp with two copper electrodes. A small gap is fabricated in the centerline of the clamp to adjust the effective length of the IPMC. The input voltage signal is produced by a power supply (model E3631A from Agilent Technologies) or by a signal generator (model 33220A from Agilent Technologies). All the signals are recorded

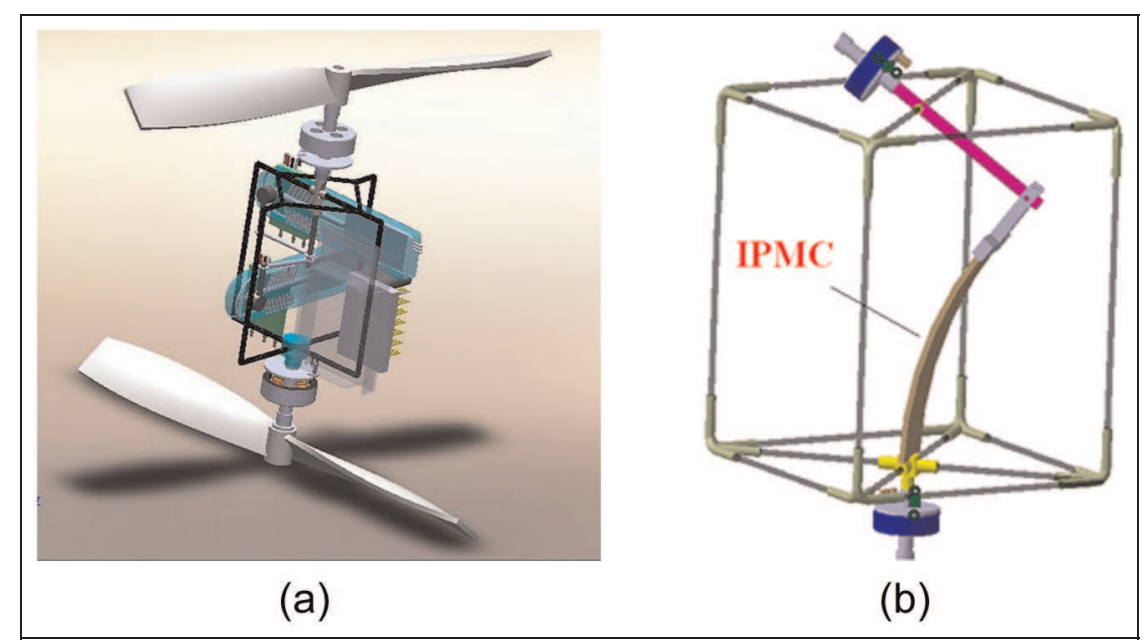

Figure I. (a) NACCOR bench model with conventional servos and (b) primary I-DOF concept of the IPMC actuator. DOF: degree of freedom; IPMC: ionic polymer-metal composite. 


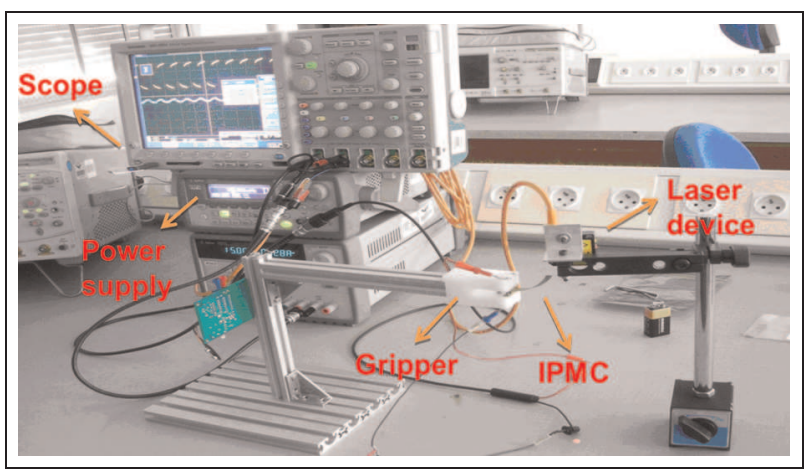

Figure 2. Photograph of experimental setup. IPMC: ionic polymer-metal composite.

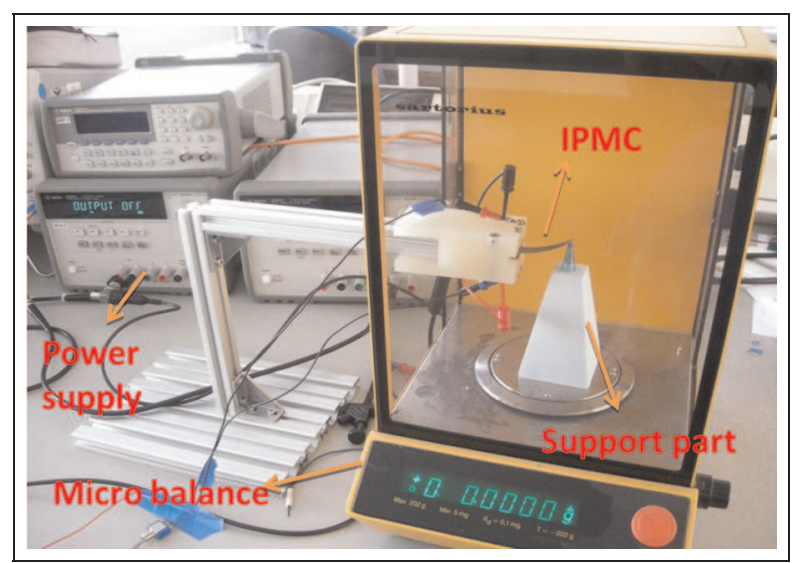

Figure 3. Blocked force measurement system. IPMC: ionic polymer-metal composite.

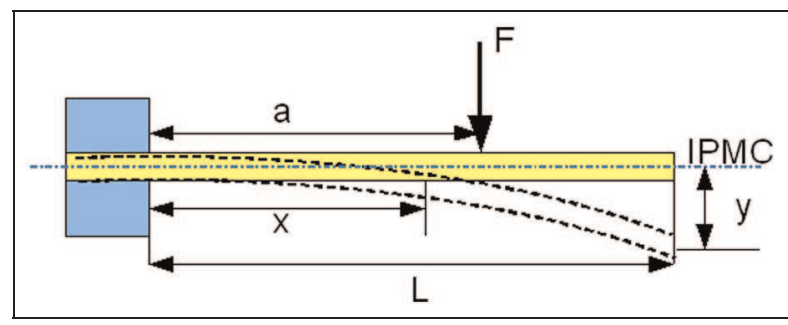

Figure 4. Schematic view of the IPMC geometry. IPMC: ionic polymer-metal composite.

by a 4-channel oscilloscope (model 54845A Infiniium from Agilent Technologies).

For measuring the blocked force, we use a micro balance (model Classical I type from Balance Sartorius) to replace the laser meter, see Figure 3. The micro balance can measure force in the range from $5 \mathrm{mg}$ to $202 \mathrm{~g}$, with a resolution of $0.1 \mathrm{mg}$. Since we have to read data from the screen, only the maximum static blocked force is measured. A special support part is fabricated and mounted on the platform of the micro balance, in order

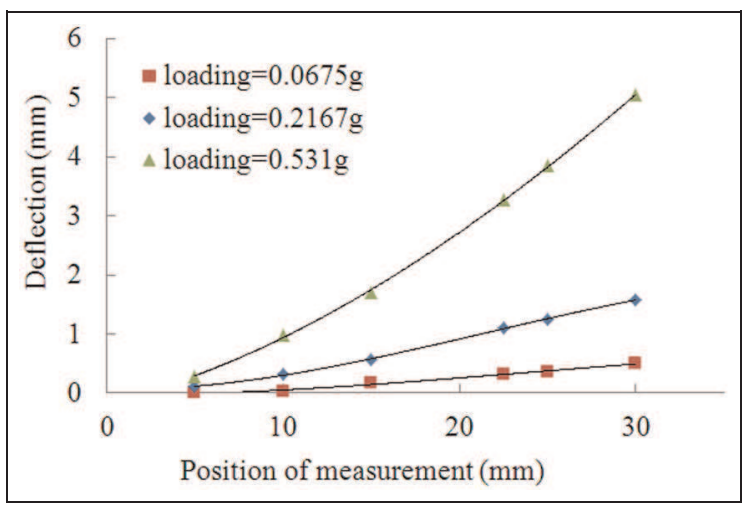

Figure 5. Bending deflection as a function of measured position along the length of the IPMC, under a $2 \mathrm{~V}$ applied voltage. IPMC: ionic polymer-metal composite.

to guarantee that only the tip of the IPMC strip acts on the force sensor.

\section{Mechanical property}

The IPMC strip is considered as a beam-like geometry, and the classical beam theory (Timoshenko, 1953) is applied to describe its mechanical behavior. As shown in Figure 4, the displacement $y$ is measured by a laser meter. The relationship between the external loading force $F$ and the Young modulus $E$ is expressed as

$$
\begin{array}{ll}
y=-\frac{F x^{2}}{6 E I}(3 a-x) & (0 \leq x \leq a) \\
y=-\frac{F a^{2}}{6 E I}(3 x-a) & (a \leq x \leq L)
\end{array}
$$

where $a$ is the effective distance between the fixed tip of the IPMC strip and the loading position; $x$ is the distance between the measured position and the fixed tip of the IPMC; $L$ is the total length of the strip; and $I$ is the moment of inertia of the IPMC, expressed as

$$
I=\frac{b h^{3}}{12}
$$

where $b, h$ are the width and thickness of the IPMC strip, respectively.

Three standard weights $\left(F_{\text {load }}=0.0675,0.2167\right.$, and $0.531 \mathrm{~g}$ ) are loaded at a certain position of the IPMC $(20 \mathrm{~mm}$ from the fixed tip). The effective length of the IPMC is $35 \mathrm{~mm}$. At six locations, ranging from 5 to $30 \mathrm{~mm}$ from the clamped tip, displacements are measured under each loading (Figure 5). The displacement of each position is measured five times to minimize the measurement error.

Equation (1) is used to calculate the stiffness (EI) of the IPMC strip. We note that the deflection is smaller when the measured position is near the clamped tip. 


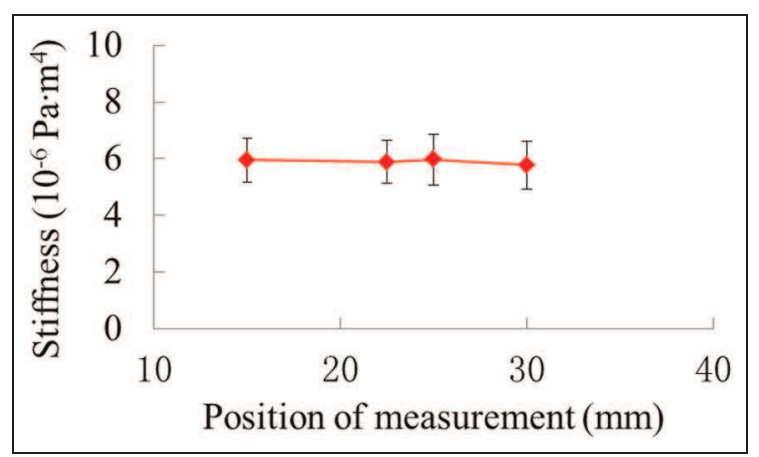

Figure 6. Measured stiffness versus position along the length of the IPMC strip.

IPMC: ionic polymer-metal composite.

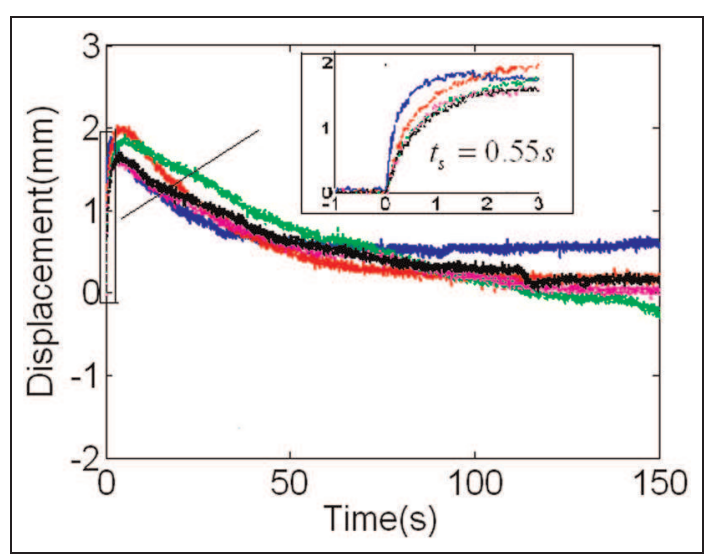

Figure 7. Tip displacement response under an applied voltage of I V $\left(\mathrm{L}_{\mathrm{eff}}=30 \mathrm{~mm}\right)$.

This leads to relatively large measurement errors at the root, due to the limited laser resolution. Therefore, only measured results in the locations of $15,22.5,25$, and $30 \mathrm{~mm}$ are used to calculate the stiffness of the IPMC. The results shown in Figure 6 demonstrate an approximate constant stiffness.

The average Young's modulus is then calculated as $E=0.262 \mathrm{GPa}$. This value is comparable to previous measurements (Bonomo et al., 2008; Branco and Dente, 2006; Kim et al., 2007; Nemat-Nasser and Wu, 2003; Nemat-Nasser and Zamani, 2003; Yim et al., 2006). In particular, Nemat-Nasser and $\mathrm{Wu}$ (2003) show that Young's modulus decreases as the water saturation increases. For Nafion-based IPMCs, a dry sample may have stiffness $\sim 10$ times greater than when it is completely saturated with water. We remark that the moment of inertia of the IPMC is $I=2.25 \times 10^{-14} \mathrm{~m}^{4}$.

\section{Bending displacement and blocked force}

In this section, we present the measured response of the IPMC under direct current (DC). We emphasize that all the measurements are carried out after the IPMC sample is fully hydrated (the IPMC strip is immersed into water more than $10 \mathrm{~h}$ before each test) at room temperature.

The displacement and blocked force are two important parameters when the IPMC is applied as an actuator. For the NACCOR application, the estimated maximum required thrust, normal force, and tilt angle of the upper rotor for a $2 \mathrm{~m} / \mathrm{s}$ translation movement are $0.15 \mathrm{~N}, 0.03 \mathrm{~N}$, and $10^{\circ}$, respectively. This means that the tip deformation of the IPMC actuator has to be larger than $2.6 \mathrm{~mm}$ under an external lateral force of about $3 \mathrm{~g}$, while the effective length of the IPMC is assumed to be $30 \mathrm{~mm}$.

First, the displacement under DC is measured initially. Figure 7 shows its response under a $1 \mathrm{~V}$ applied voltage, with five curves corresponding to tests carried out on five different days. We remark that all these tests are carried out under the same operating conditions. We find that the IPMC actuator has an acceptable level of repeatability on a relatively short time scale (less than $1 \mathrm{~s}$ ), which is obviously very important for NAV application. Under a DC operating voltage regime, the IPMC bends toward its maximum displacement, with a settling time of about half second. After reaching the maximum deformation, the IPMC shows a slow back relaxation, which has been observed and analyzed by several researchers. This phenomenon was explained to be the diffusion effect of the water molecules due to the difference of water density, under a voltage driving signal. Some researches have stated that this back relaxation can be avoided if a current driving signal is applied (Branco and Dente, 2006; Branco et al., 2012). In this paper, its basic principles are not intended to be discussed any further and interested readers can refer to reference works (Nemat-Nasser and Zamani, 2003; Shahinpoor et al., 1998). The maximum displacement achieved by the IPMC initially increases with the applied voltage (Figure 8), but for an amplitude of the applied voltage larger than $4.5 \mathrm{~V}$, the IPMC displacement stays constant, revealing a saturation process and corresponding to the maximum bending ability of the IPMC. A similar phenomenon is observed by Kim et al. (2007). This saturation is due to the electrolysis of the water solvent in high electric fields (Branco et al., 2012).

For applications, such as the NACCOR system, the influence of a static external moment on the work characteristic of the IPMC has to be investigated. As shown in Figure 9, the externally applied moment $M=9.92 \mathrm{gmm}$ has a small influence on the performance of the IPMC actuation (the IPMC has an effective length of $20 \mathrm{~mm}$ ). We note that this external force is about 10 times of its own weight of IPMC, but there is negligible influence on the displacement.

The term "blocked force" here means the maximum tip force produced with zero deformation, while a 


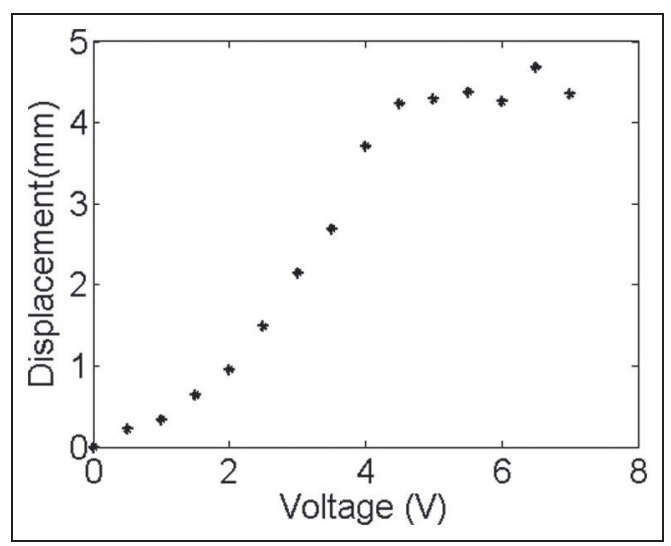

Figure 8. Maximum displacement versus amplitude of the applied voltage $\left(\mathrm{L}_{\text {eff }}=30 \mathrm{~mm}\right.$, measured position at the middle of the strip).

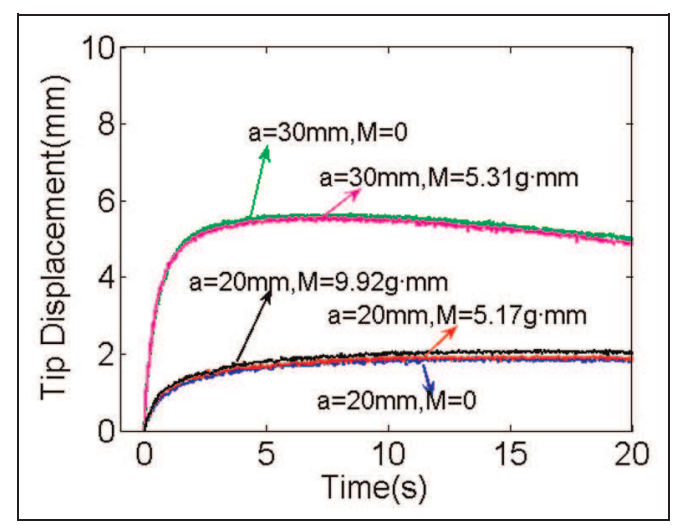

Figure 9. Comparison of the tip displacement under different effective lengths and external loadings (applied voltage: $2 \mathrm{~V}$ ).

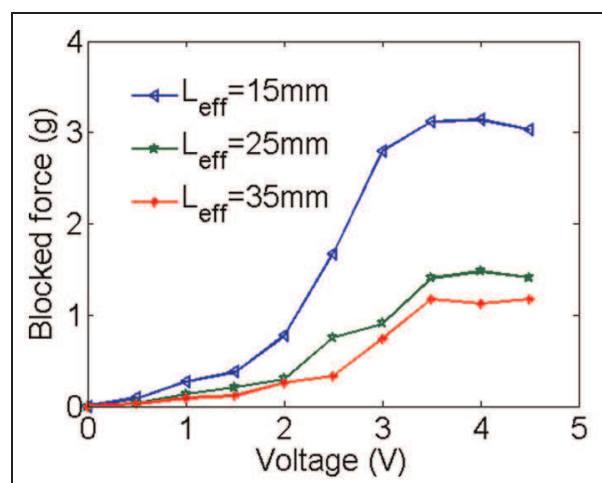

(a)

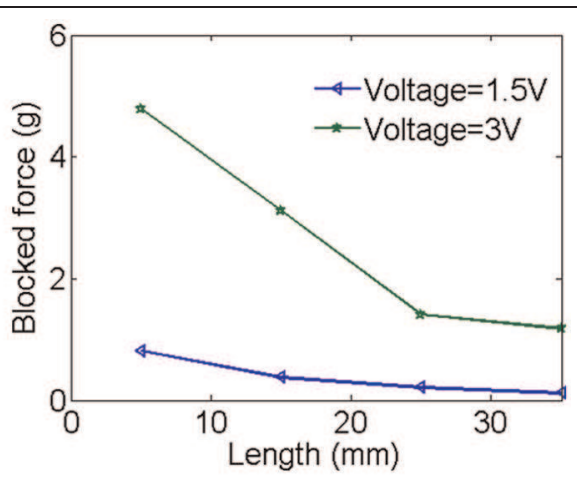

(b)

Figure 10. (a) Blocked force versus amplitude of the applied voltage for different effective lengths of the IPMC and (b) blocked force versus effective length under different applied voltages. IPMC: ionic polymer-metal composite.

voltage is applied between the two electrodes of the IPMC. Figure 10(a) shows that the blocked force increases as the input voltage increases when the applied voltage is smaller than $3.5 \mathrm{~V}$. However, the blocked force saturates at higher voltages. This phenomenon exhibits a similar trend as for the deformation response, as presented in Figure 8. Kim et al. (2007) observed a similar trend in their measurements. This phenomenon is also due to the water electrolysis when a high voltage is applied (Barramba et al., 2007). Three different effective lengths of the IPMC are measured, which are 15,25 , and $35 \mathrm{~mm}$, respectively. The corresponding maximum blocked forces generated by three lengths are $3.108,1.403$, and $1.147 \mathrm{~g}$, which are $41.44,11.22$, and 6.55 times of its own weight of the IPMC, respectively.

Figure 10(b) shows the blocked force as a function of the effective length, under two different applied voltages. A strong nonlinear relation is observed between the maximum blocked force and the effective length.
This indicates that shorter IPMC strips actuate better.

\section{Modeling analysis}

\section{Modeling classification}

In the past decades, much effort has been devoted to describe the sensor/actuation principle of IPMCs for various applications. Normally, the models can be categorized into three types. "Black box" models (Kanno et al., 1994; Truong et al., 2010) are fully based on experimental observations. The advantage of this model is its simplicity, but it is not easily extended to other devices and is too simple to guarantee sufficiently accurate predictions. The second type of models is the "white box" models. The "white box" models are typically fully based on the physical and chemical properties of the material, for example, the Poisson-Nernst-Planck model to understand the role of the polymer-metal 


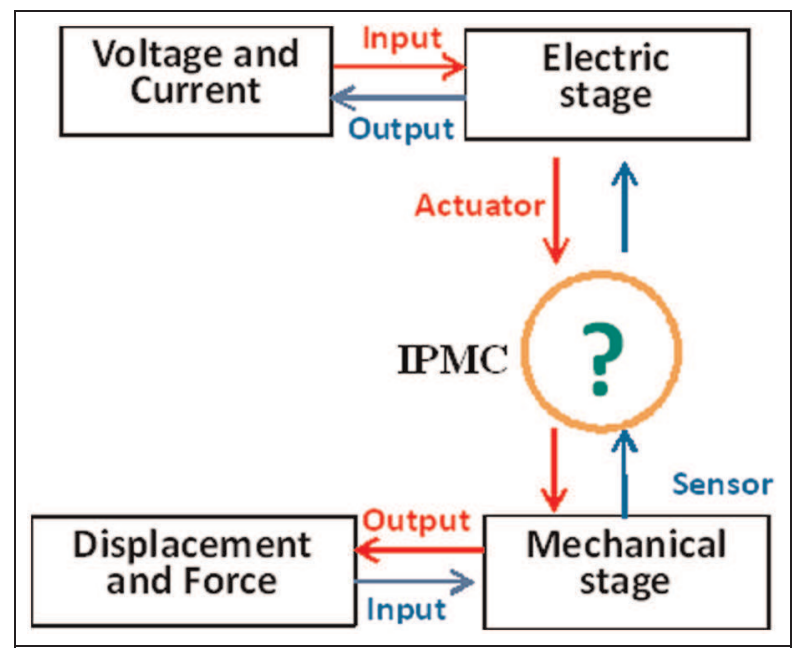

Figure I I. Schematic of electromechanical conversion of IPMCs.

IPMC: ionic polymer-metal composite.

interfaces on IPMCs behavior (Aureli et al., 2009; Cha et al., 2012; Cha and Porfiri, 2013; Porfiri, 2008, 2009a, 2009b), sensor model (Aureli and Porfiri, 2013; Bahramzadeh and Shahinpoor, 2011; Chen et al., 2007; Farinholt and Leo, 2004; Pugal et al., 2010; Zangrilli and Weiland, 2011), and the linear or nonlinear actuation model (Akle et al., 2011; Branco and Dente, 2006; Chen and Tan, 2008; Del Bufalo et al., 2008; Fotsing and Tan, 2012; Galante et al., 2013; Nardinocchi et al., 2011; Wallmersperger et al., 2007). However, the parameters of white box models are normally hard to verify, and complicated partial differential equations have to be solved to explain the underlying physics. At an intermediate level, for practical real-word engineering applications, "gray-box" models represent useful choices, which are based on a set of simple equations that describe a known class of phenomena (De Gennes et al., 2000; Lee et al., 2011b; Newbury and Leo, 2003), combined with some parameters that are experimentally determined. In particular, Lin et al. (2009) developed an empirical model for closed-loop control of IPMCs. Vahabi et al. (2011) and Bhandariet al. (2012) presented comprehensive reviews on the development of IPMC models. Beyond the model category, models can be categorized into static or dynamic types depending on whether the time-variant characteristics of IPMCs are considered.

In this article, two models developed by De Gennes et al. (2000) and Bar-Cohen (2004) are utilized to study the static and dynamic characteristics of the IPMC, respectively. The objective of the current work is to find the connection between electrical and mechanical stages, as illustrated in Figure 11, which is the premise and foundation of controlling IPMCs. Some critical coefficients for the models are extracted from experimental measurements, which will be introduced in detail in the next section.

\section{Static linear irreversible electro-dynamical model}

The principle of IPMC actuation/sensor phenomenon is derived from the standard formulation of the Onsager equations, using linear irreversible electrodynamics, see De Gennes et al. (2000) for a detailed derivation. When static conditions are imposed, a simple description of the electromechanical effects is possible based on two forms of transport: ion transport (with a current density, $J$ ) and solvent transport (with a flux, $Q$, here assumed to be water flux). The conjugated force includes the electric field $E$ and the pressure gradient $\nabla p$. The resulting equation is

$$
\left(\begin{array}{c}
J \\
Q
\end{array}\right)=\left[\begin{array}{cc}
\sigma & -L_{12} \\
L_{21} & -K
\end{array}\right]\left(\begin{array}{c}
E \\
\nabla p
\end{array}\right)
$$

Here, $\sigma$ is the membrane conductivity, $K$ is the Darcy permeability, and $L_{12}=L_{21}=L$ is a cross-effect coefficient, which is related to the charge-to-mass ratio of ion molecules of the electrolyte (Branco and Dente, 2006).

Direct effect. The "direct effect," or actuation mode, is first considered assuming that electrodes are ideally impermeable to water

$$
\nabla p=\frac{L}{K} E \quad \text { with } \quad Q=0
$$

The pressure gradient $\nabla p$ induces a curvature $\kappa$ proportional to $\nabla p$, which can be expressed as (Shahinpoor and Kim, 2004)

$$
\kappa \approx \frac{\nabla p}{Y}=\frac{L}{K Y} E
$$

where $Y$ is Young's modulus of the IPMC strip.

Inverse effect. The "inverse effect," or sensor mode, corresponds to the state in which a bending torque $\Gamma$ is applied to the membrane, under the conditions that no electric work is produced $(J=0)$ and the strip stays flat

$$
E=\frac{L}{\sigma} \nabla p
$$

It has to be noted that the conductivity $\sigma$ in equations (3) and (6) is the conductivity at constant water pressure $(\nabla p=0$, in other words, the IPMC strip is blocked). But if we measure the conductivity at zero water flux, another value is obtained 


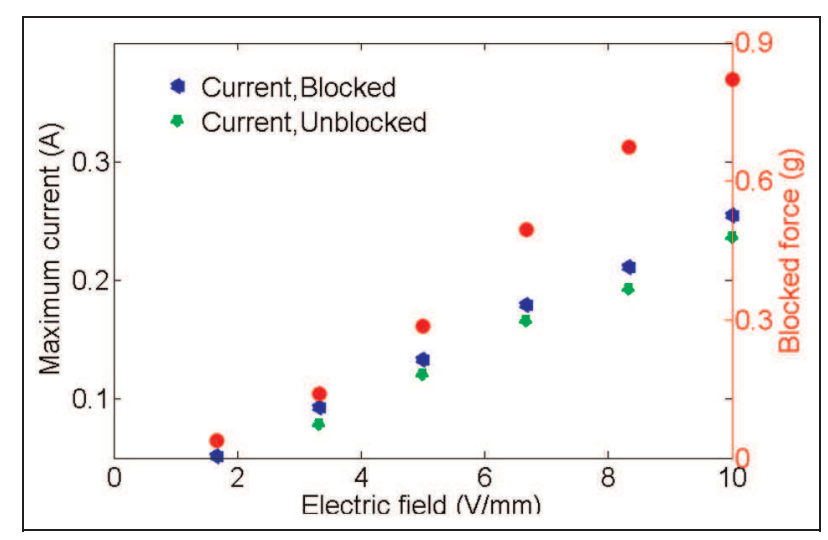

Figure 12. Measured maximum current and blocked force versus electric field $\left(L_{\text {eff }}=30 \mathrm{~mm}\right)$.

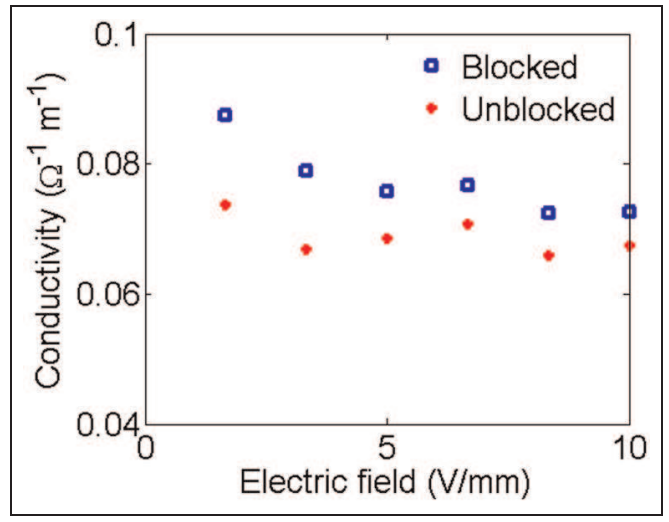

Figure I3. Evaluated conductivity versus electric field.

$$
\tilde{\sigma}=\sigma-\frac{L^{2}}{K}
$$

With the above theoretical analysis, we can investigate the electrical property of IPMCs. Figure 12 shows experimental results of maximum current and blocked force versus electric field. The driving signal is DC and the IPMC strip has an effective length of $30 \mathrm{~mm}$. As presented in Figure 10, saturation is observed for the blocked force when the applied voltage is larger than $3.5 \mathrm{~V}$; thus, the input voltage is set from 0.5 to $3 \mathrm{~V}$ in this test case, with an interval of $0.5 \mathrm{~V}$. The maximum current when the tip of the IPMC strip was blocked is a little larger than for the unblocked case. This result is acceptable according to the negative term of equation (3) while the IPMC is unblocked, and $\nabla p=0$ in the blocked case. Two conductivities are obtained, as shown in Figure 13, thank to equations (3), (4), and (7). The average conductivities are $\sigma \approx 0.077 \Omega^{-1} \mathrm{~m}^{-1}$ and $\tilde{\sigma} \approx 0.068 \Omega^{-1} \mathrm{~m}^{-1}$.

Torque and electric response. When the "direct effect" and the "inverse effect" are combined, an electric field $E$ and a mechanical torque $\Gamma$ (per unit width) are applied at the same moment. So, the effect of the electric field and the torque on the curvature cancel out and the sample stays flat $(\kappa=0)$. In those conditions, the torque should fulfill the following requirement

$$
\Gamma=\frac{1}{12} \frac{1-2 \sigma_{p}}{1-\sigma_{p}} \frac{L h^{3}}{K} E
$$

where $h$ is the thickness of the IPMC strip, $\sigma_{p}$ is the Poisson ratio.

When a finite water flux $Q$ is imposed, and $J=0, \kappa=0$, a certain field $E$ is derived from equation (6)

$$
E=\frac{12\left(1-\sigma_{p}\right)}{1-2 \sigma_{p}} \frac{L}{\sigma h^{3}} \Gamma
$$

The ratio of the two coefficients derived from equations (8) and (9) is

$$
\rho=\frac{\left(\frac{\Gamma}{E}\right)_{\text {direct }}}{\left(\frac{\Gamma}{E}\right)_{\text {inverse }}}=\frac{L^{2}}{\sigma K}
$$

Besides the membrane conductivity $\sigma$, two other parameters are also very important, namely the Darcy permeability $K$ and the cross-effect coefficient $L$. They need to be verified according to the measurement of the blocked force (equivalent to the mechanical torque $\Gamma$ in equation (8)) and the electric current.

The equivalent mechanical torque $\Gamma$ can be derived from the blocked force $F_{b}$

$$
\Gamma=\frac{F_{b} l_{e}}{w}
$$

where $l_{e}$ and $w$ are the effective length and width of the IPMC strip, respectively.

The process of parameter identification can be summarized as follows. First, since two conductivities are derived, the ratio of $L^{2} / K$ could be deduced from equation (7). Second, the relation between mechanical torque $\Gamma$ and electric field $E$ is obtained from equation (9); thus, the ratio of $L / K$ is evaluated according to equation (8). Finally, $L$ and $K$ are calculated, and the ratio between actuation and sensor modes is then derived by equation (10).

Figure 14 shows how the experimental results of $L / K$ and $L / \sigma$ vary with applied electric field, which are the slopes in equations (4) and (6), that is, in actuation and sensor modes, respectively. The Poisson ratio is assumed to be $\sigma_{p}=0.4 . L / K$ increases with the electric field, and this behavior can be fitted by a quadratic function. A similar trend was obtained in a previous investigation (Shahinpoor and Kim, 2004).

Assuming that the IPMC strip exhibits a linear elasticity, the stress $\sigma_{b}$ can be calculated using Hooke's law 


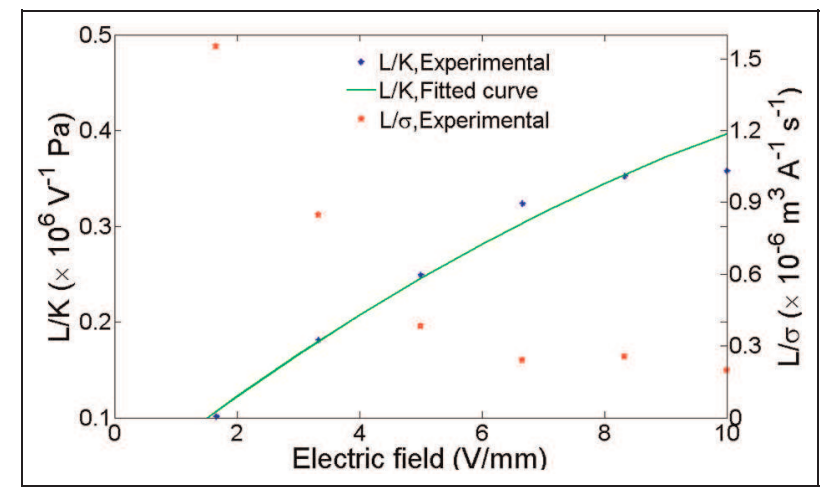

Figure 14. Experimental determination of coefficients $L / K$ and $L / \sigma$ versus electric field.

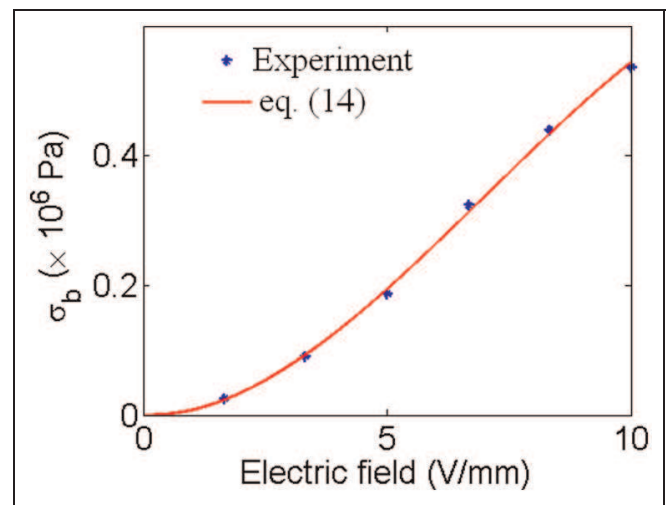

Figure 15. Maximum stresses generated by the IPMC versus electric field.

IPMC: ionic polymer-metal composite.v

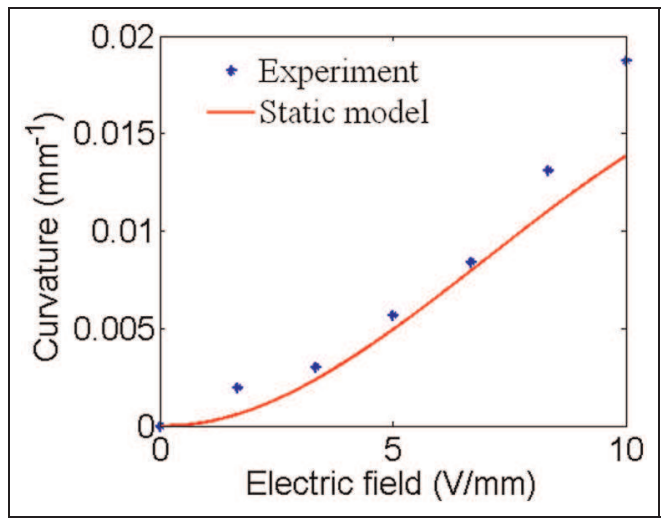

Figure 16. Curvature response of the IPMC versus electric field.

IPMC: ionic polymer-metal composite.

$$
\sigma_{b}=\frac{M h}{2 I}
$$

where $M=F_{b} l_{e}$ is the equivalent moment produced by the blocked force $F_{b}$.
With the blocked force measured in Figure 12, the stress can be obtained by equation (12). The pressure gradient can be estimated as (Shahinpoor and Kim, 2001)

$$
\nabla p \approx \frac{2 \sigma_{b}}{h}
$$

Combining equation (13) with equation (4), a theoretic estimate of stress is expressed as

$$
\sigma_{b} \approx \frac{h}{2} \frac{L}{K} \cdot E
$$

It should be noted that $L / K$ is a quadratic function of the electric field, whose coefficients are derived by the curve fitting, as shown in Figure 14. The comparison of the maximum stress between the theoretical prediction and the experimental data fits very well, as shown in Figure 15. We conclude that the static model accurately describes the mechanical characteristic of the IPMC.

Furthermore, the predicted curvature response is compared with the experimental measurements to validate the measured coefficients of the Onsager equations. The conversion efficiency between actuator mode and sensor mode is compared as well.

From Figure 8, the experimental curvature is derived based on equation (15), since an approximately linear relation (Shahinpoor, 2003) between bending displacement and curvature can be used

$$
\kappa \approx \frac{2 \delta_{c}}{l_{c}^{2}+\delta_{c}^{2}} \approx \frac{2 \delta_{c}}{l_{c}^{2}}
$$

where $\delta_{c}$ is the maximum displacement at a certain measured length $l_{c}$ of the IPMC strip.

It has to be noted that the theoretical curvature response of the static model is obtained by equation (5). The curvature is in agreement with the experimental data, as shown in Figure 16. The slight differences can be explained by the constant Young's modulus used in equation (5), which varies with electric field, temperature, and hydration (Nemat-Nasser and $\mathrm{Wu}$, 2003).

Figure 17 shows the torque versus the electric field. The responses of the IPMC on actuation mode and sensor mode are compared. The theoretical and experimental results are in good agreement with actuation mode, while the experimental results of sensor mode are not tested due to the current experimental limitations. The evaluated coefficients of the Onsager equations are $K \approx 1.12 \times 10^{-17} \mathrm{~m}^{2} / \mathrm{cP}$, where $1 \mathrm{cP}=1 \mathrm{mPas}$ and $L \approx 4.29 \times 10^{-8} \mathrm{~m}^{2} \mathrm{~V}^{-1} \mathrm{~s}^{-1}$, which are in agreement with the measurements of Shahinpoor and Kim (2001, 2004). The ratio of actuation and sensor modes in equation (10) can explain that the actuation mode of the IPMC is more efficient than the sensor mode, for 


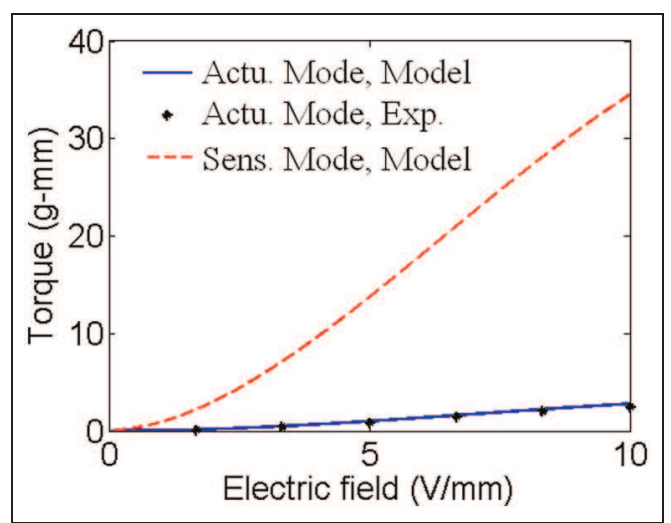

Figure 17. Comparison of torque between actuation mode and sensor mode versus electric field.

the tested IPMC sample. In other words, imposing a deformation creates an electric field (sensor mode) much smaller than the electric field necessary to generate the same deformation (actuation mode). As we focus on the actuation mode in this article, more accurate devices and detailed measurements should be implemented for the sensor mode in the future work.

\section{Phenomenological dynamic model}

To study the time-dependent characteristics of IPMCs, a dynamic model developed by Bar-Cohen (2004) and Xiao and Bhattacharya (2001) is used in this article. The transfer function from driving voltage to mechanical deformation of the IPMC strip is derived.

In general, the IPMC is regarded as consisting of two parallel electrodes and an electrolyte between the electrodes in dynamic models. The capacitance and the internal resistance of the electrolyte can be modeled as a simple resistor and capacitor (RC) circuit. If a possible leakage is considered, a ( $\mathrm{RC}) \| \mathrm{R}$ circuit can be constructed. In this article, the analytical model is developed based on the lumped RC model of IPMCs (Bao et al., 2002; Yim et al., 2006). As shown in Figure 18(a), $r_{1}$ is the internal resistance between the electrodes, $C$ is the capacitance, and $r_{2}$ is the resistance of possible leakage. Under DC, considering the internal resistance $\left(r_{0}\right)$ of the power supply, the response current is given by

$$
I(t)=\frac{U}{r_{0}+r_{2}}\left[1+\left(\frac{r_{1}+r_{2}}{R}-1\right) e^{-\alpha t}\right]
$$

where

$$
\begin{gathered}
R=r_{1}+\frac{r_{0} r_{2}}{r_{0}+r_{2}} \\
\alpha=\frac{1}{R C}
\end{gathered}
$$

On the basis of a lumped RC circuit model, the electric charge on the electrode is described by

$$
R \frac{d q}{d t}=U-\frac{q}{C}
$$

where $C$ is the capacitance of the IPMC.

A "three-element" method (Tang, 2003) is utilized to derive parameters $r_{1}, r_{2}$, and $C$, while two voltage meters are used to record the voltage values. The calculated results are presented in Table 1. Compared to previous experiments (Abdelnour et al., 2012; Bao et al., 2002; Jung et al., 2003; Yim et al., 2006), the capacitance $C$ of the IPMC and its resistance $r_{2}$ (which dominates its steady-state response) are in agreement. However, the resistance of the IPMC $r_{1}$ is smaller in our test. The reason is not clear at this moment, because the resistance of the IPMC depends on many factors, such as the type of cations, the hydration level, and the thickness of the IPMC.

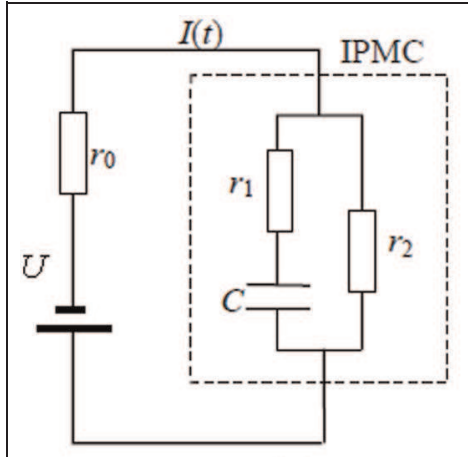

(a)

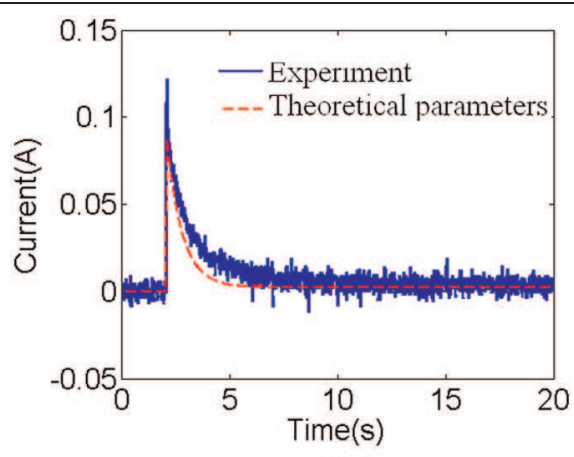

(b)

Figure 18. (a) Lumped RC model of the IPMC and (b) the comparison of the electric current between the experimental data and the theoretical curve of equation (I6), under a I V applied voltage.

RC: resistor and capacitor; IPMC: ionic polymer-metal composite. 
Table I. Parameters of the lumped RC circuit.

\begin{tabular}{lcc}
\hline$r_{1}$ & $r_{2}$ & $C$ \\
\hline$\sim 7-13 \Omega$ & $\sim 265 \Omega$ & $\sim 6.5 \times 10^{-2} \mathrm{~F}$ \\
\hline
\end{tabular}

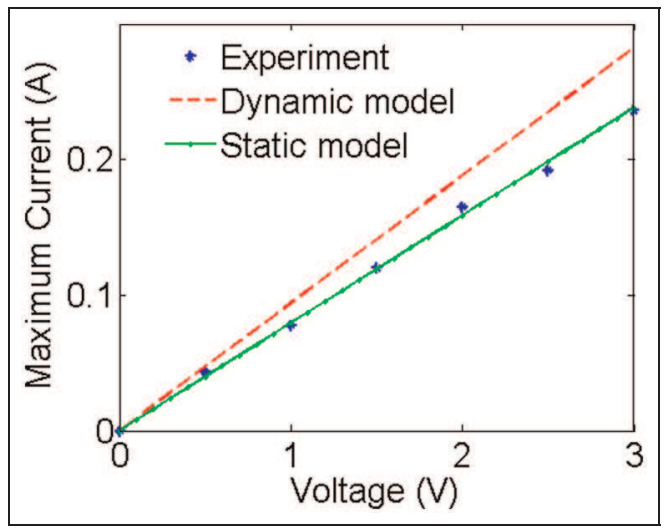

Figure 19. Initial maximum current versus amplitude of the applied voltage.

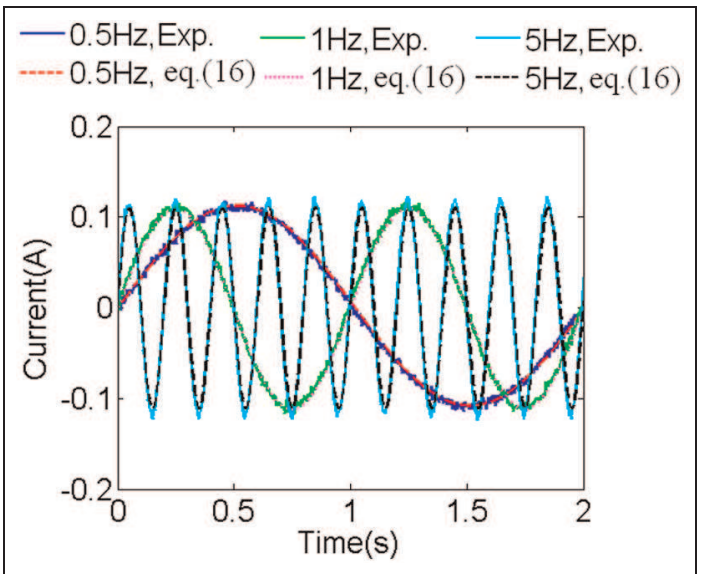

Figure 20. Electric current response under sinusoidal driving voltage.

The theoretical initial maximum current of the IPMC based on the lumped RC model of equation (16) is given by

$$
I(0) \approx \frac{U}{r_{0}+r_{1}}
$$

The resistance $r_{1}$ is in the range of $7-13 \Omega$, according to multiple measurements. In the static model, the IPMC is assumed to have a constant resistance and the equivalent resistance is evaluated as $r=11.5 \Omega$. The measured resistances are comparable in the above two different models. Figure 18(b) presents the comparison of experimental and theoretical current responses under a $1 \mathrm{~V}$ applied voltage, which are in good agreement. The maximum current as a function of the amplitude of the applied voltage is compared between experiment and model, see Figure 19. We note that the maximum current is obtained at the initial time. The initial current is approximately a linear function of the applied voltage, for both the experimental data and the model prediction. The same linear relation is observed in the experiments of Chen et al. (2009). Therefore, we conclude that the lumped RC model can capture both the steadystate and time transient characteristics of the electric current under DC.

We also present the electric current response under sinusoidal voltages for three frequencies, $0.5,1$, and $5 \mathrm{~Hz}$, respectively. The amplitude of the sinusoidal voltage signal (produced by a generator of model 33220A from Agilent Technologies) is set as $3.7 \mathrm{~V}$ (corresponding to a realistic working voltage for the NACCOR system). Due to the internal resistance of the generator $(50 \Omega)$, the real amplitude of the voltage applied to the IPMC is about $1.4 \mathrm{~V}$. Figure 20 shows that the lumped model predicts the current response under alternating current (AC) signals very well.

Assuming that the IPMC actuator works as an ideal cantilever beam, the bending curvature should be uniform along the length of the strip. Previous studies indicate that the response of the IPMC strongly depends on it backbone polymer and the type of mobile counter ions (Nemat-Nasser and $\mathrm{Wu}, 2003)$. In this article, the counter ions of the IPMC sample are $\mathrm{Na}^{+}$. Under a constant driving voltage, the strip shows a slow relaxation toward the cathode after a very rapid initial bending toward the anode (as shown in Figure 7). Assuming that the positive ions bring more water to the cathode than the water that is present in equilibrium, the model is constructed based on the following mechanism. The eigen-curvature varies with time and is described by

$$
\frac{d \kappa}{d t}=K_{1} \frac{d q}{d t}-\frac{1}{\tau_{2}}\left(\kappa-K_{2} q\right)
$$

where $\kappa$ is the curvature of the strip, $q$ is the electric charge, $K_{1}$ is the coefficient for the bending effect of the charge freshly moving to the electrode, $K_{2}$ is the coefficient for the bending effect of the charge in equilibrium, and $\tau_{2}$ is the relaxation time constant.

Assuming that $\kappa(0)=0$, combining equation (19) with equation (21) gives

$$
\kappa=U\left(K_{v 2}-\frac{K_{v 1} \tau_{2}-K_{v 2} \tau_{1}}{\tau_{2}-\tau_{1}} e^{-t / \tau_{1}}+\frac{\tau_{2}\left(K_{v 1}-K_{v 2}\right)}{\tau_{2}-\tau_{1}} e^{-t / \tau_{2}}\right)
$$

where $\tau_{1}=R C$ is the time constant of the electric circuit, and $K_{v 1}=C K_{1}, K_{v 2}=C K_{2}$.

Substituting equation (15) into equation (22) and expressed in the frequency domain, the transfer 
Table 2. Curve fitting coefficients of the time-variant model.

\begin{tabular}{lllc}
\hline$K v_{1}$ & $K v_{2}$ & $\tau_{1}(=\mathrm{RC})$ & $\tau_{2}$ \\
\hline $4.39(\mathrm{~m} \mathrm{~V})^{-1}$ & $0.66(\mathrm{~m} \mathrm{~V})^{-1}$ & $0.55 \mathrm{~s}$ & $28.18 \mathrm{~s}$ \\
\hline
\end{tabular}

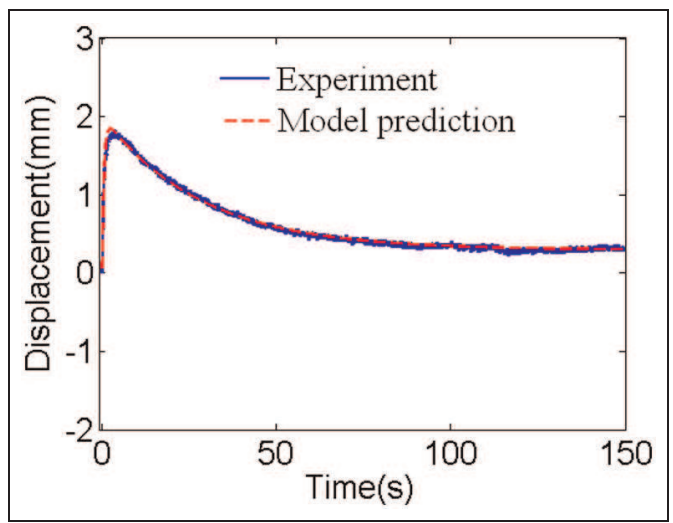

Figure 2I. Comparison of experimental and curve-fitted of equation (22) tip displacement responses under a I $\mathrm{V}$ applied voltage $\left(L_{\text {eff }}=30 \mathrm{~mm}\right)$.

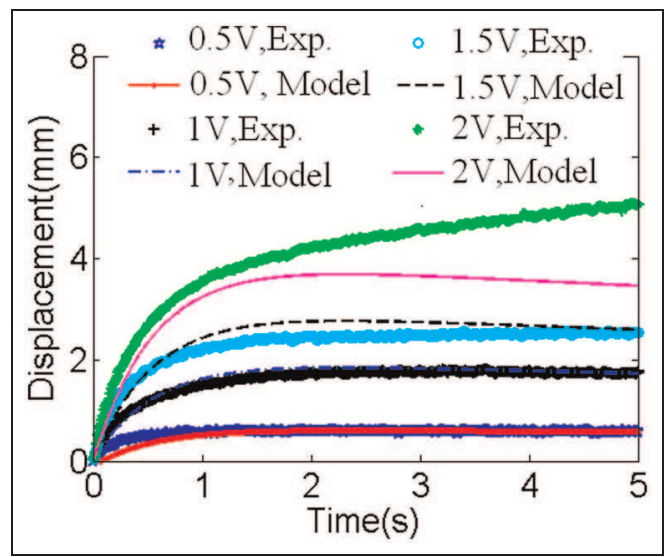

Figure 22. Tip displacement comparison between the timevariant model and the experimental data under DC $\left(\mathrm{L}_{\mathrm{eff}}=30 \mathrm{~mm}\right)$.

DC: direct current.

function from driving voltage to displacement response of the IPMC is

$$
G(s)=\frac{\delta(s)}{U(s)}=\frac{C}{1+\tau_{1} s} \cdot \frac{K_{1} \tau_{2} s+K_{2}}{1+\tau_{2} s} \cdot l_{c}^{2} / 2
$$

where $s$ is a Laplace complex variable.

As shown in Figure 21, the displacement response is obtained by averaging five experimental tests, see Figure 7. A MATLAB command for least-squares curve fitting LSQCURVEFIT is used to derive the logical parameters of equation (23), and the coefficients are shown in Table 2. These values are in agreement with Bao et al. (2002). We get

$$
G(s)=\frac{4.8599(s+0.0053)}{(s+1.808)(s+0.03548)}
$$

It has to be noted that the displacement obtained from equation (24) is expressed in millimeter. The comparison between simulation with fitted parameters and experiment is present in Figure 21, which shows a good agreement. The theoretical and experimental responses of the displacement under different amplitudes of DC $(0.5,1,1.5$, and $2 \mathrm{~V})$ are compared in Figure 22. It shows that the response less than $2 \mathrm{~V}$ under DC is in good agreement. The difference between the theoretical prediction and the experimental data increases with the amplitude of the applied voltage. The divergence is due to the electrolysis phenomenon that happens under higher applied voltages (Barramba et al., 2007). On the other hand, the nonlinear characteristics of the IPMC affect its displacement response, which is still not fully understood.

\section{Power efficiency}

For self-contained vehicle system, power consumption is a critical parameter that influences the operational time of vehicles powered by batteries. In an air-operable application, proper encapsulation is critical to prevent evaporation of the electrolyte (Barramba et al., 2007). For simplicity, we neglect these factors here and assume that the samples are fully hydrated. The power efficiency for different driving AC signals is studied, using the dynamic model developed above. The experimental measurement of the response under AC input voltage is shown in Figure 23, which presents the maximum displacement and the power consumption as a function of the frequency of the driving AC signal. Three waveforms are tested: sinusoidal, square, and triangular. We found that the displacement decreases as the frequency increases for each type of signals. The reason of this decrease is the reduction in the time to respond of the actuator with a high frequency. The square input voltage generates a larger displacement than the other two waveforms. However, we cannot conclude that the square waveform is better, because the square waveform consumes more electric power compared to others, as shown in Figure 23(b). Similar conclusions are reported by Jung et al. $(2003,2011)$ and Yun et al. (2008).

The power efficiency of three waveforms is compared using the dynamic model. The root mean square power $P_{R M S}$ of an input signal is expressed as

$$
P_{R M S}=\frac{2}{T} \cdot \int_{0}^{T / 2} V(t) \cdot I(t) \cdot d t
$$




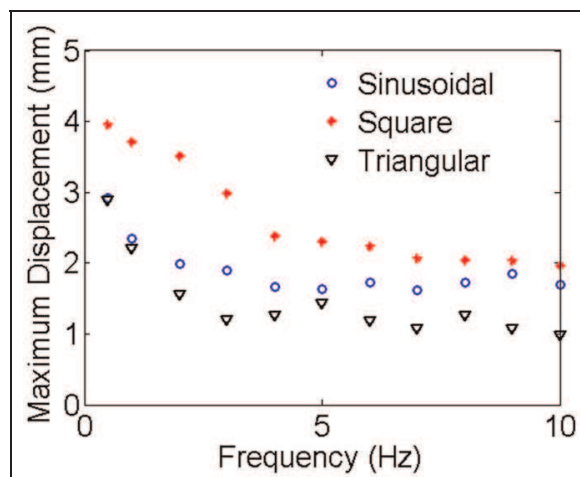

(a)

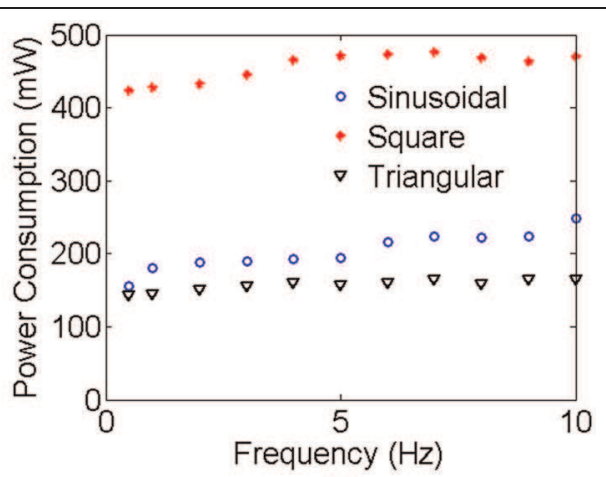

(b)

Figure 23. (a) Displacement and (b) power consumption versus driving frequency, according to different waveforms (the amplitude of the voltage $\mathrm{V}_{\mathrm{PP}}= \pm 4 \mathrm{~V}$ ).

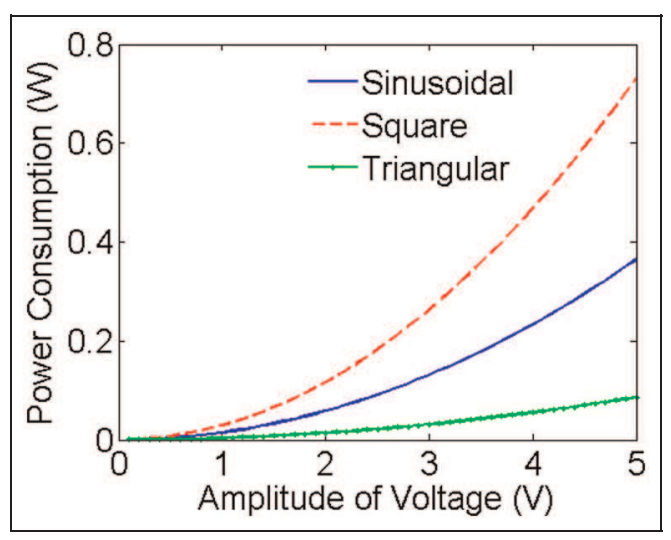

Figure 24. Power consumption versus amplitude of the voltage for three waveforms, with a frequency of $0.2 \mathrm{~Hz}$.

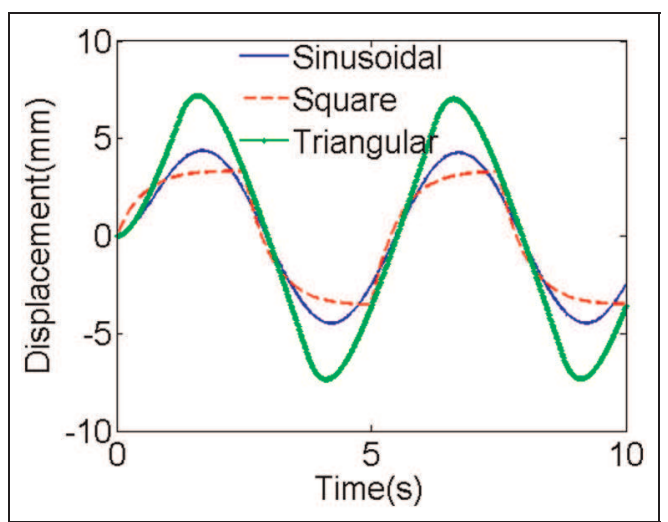

Figure 25. Numerical displacement comparison between three waveforms, under an input power of $100 \mathrm{~mW}$ and a frequency of $0.2 \mathrm{~Hz}$.

where $T$ is the period of the signal, and the electric current $I(t)$ is calculated by equation (16).

The power consumption as a function of the voltage amplitude is compared in Figure 24, at a fixed frequency of $0.2 \mathrm{~Hz}$ for three waveforms. It shows that the power consumption increases with the amplitude of the voltage. The square driving signal consumes the largest amount of power. To compare the power efficiency, we test the amplitude of the voltage for the three waveforms with a constant power output of $100 \mathrm{~mW}$. They are $1.8,2.7$, and $5.2 \mathrm{~V}$, corresponding to square, sinusoidal, and triangular waveforms, respectively. From the transfer function of equation (24), the displacement response is shown in Figure 25, under the same power consumption for the three waveforms. It shows that the driving signal by the square waveform has the lowest efficiency.

We therefore conclude that the driving signal waveform has great effect on the power consumption. The square waveform, with an abrupt change of its slope, should be avoided due to its high-frequency component. As the power consumption increases with the frequency (Figure 23(b)), the IPMC actuator should work at a frequency as low as possible.

\section{Conclusion}

In this article, we characterize the performance of an IPMC actuator in air for a vehicle application. We investigate its static and dynamic behaviors both experimentally and theoretically.

The mechanical properties of the IPMC sample are measured first. It has a Young's modulus of $2.62 \times 10^{8} \mathrm{~Pa}$. The displacement response is measured under DC driving voltages. The maximum displacement is proportional to the amplitude of the applied voltage, until its deformation is saturated. The tip displacement increases with the effective length of the strip, and an external loading of 10 times the IPMC weight has almost no effect on its displacement response. The maximum blocked force produced by three effective lengths, $L=35,25$, and $15 \mathrm{~mm}$, are 6.55 , 11.22, and 41.44 times the IPMC strip weight. We conclude that the blocked force increases as a nonlinear 
function of the effective length, and short samples are compatible with weight-restricted applications.

Two analytical models are developed based on the experimental data. The coefficients of the Onsager equations are verified within the framework of the linear irreversible electro-dynamical approach, which accurately predicts the characteristics of the IPMC in the steady state. The static model shows that the efficiency of the actuation mode is higher than that of the sensor mode. A dynamic model is used to relate the deformation response to the driving voltage, with the back relaxation being described phenomenologically. The power efficiency of different waveforms and frequencies is investigated. To save the power for the selfcontained vehicle system, we should avoid a driving signal with an abrupt slope and a high frequency.

\section{Acknowledgements}

The authors would like to thank Sébastien MAJSAK, Philippe MOULIGNE, and Patrick MOREL for their help in designing the test bench. The authors also thank the reviewers for their constructive comments that have helped improve this article.

\section{Declaration of conflicting interests}

The authors declared no potential conflicts of interest with respect to the research, authorship, and/or publication of this article.

\section{Funding}

This research was supported by financial funding of Sciences et Technologies pour l'Aéronautique et l'Espace (STAE) and the EMMAV project.

\section{References}

Abdelnour K, Stinchcombe A, Porfiri M, et al. (2012) Wireless powering of ionic polymer metal composites toward hovering microswimmers. IEEE/ASME Transactions on Mechatronics 17(5): 924-934.

Abdulsadda AT and Tan XB (2012) An artificial lateral line system using IPMC sensor arrays. International Journal of Smart and Nano Materials 3(3): 226-242.

Akle BJ, Habchi W, Wallmersperger T, et al. (2011) High surface area electrodes in ionic polymer transducers: numerical and experimental investigations of the electro-chemical behavior. Journal of Applied Physics 109(7): 074509-1074509-8.

Aureli M and Porfiri M (2013) Nonlinear sensing of ionic polymer metal composites. Continuum Mechanics and Thermodynamics 25(2): 273-310.

Aureli M, Kopman V and Porfiri M (2010) Free-locomotion of underwater vehicles actuated by ionic polymer metal composites. IEEE/ASME Transactions on Mechatronics 15(4): 603-614.

Aureli M, Lin WY and Porfiri M (2009) On the capacitanceboost of ionic polymer metal composites due to electroless plating: theory and experiments. Journal of Applied Physics 105(10): 104911-1-104911-13.
Aureli M, Prince C, Porfiri M, et al. (2010) Energy harvesting from base excitation of ionic polymer metal composites in fluid environments. Smart Materials and Structures 19(1): 015003.

Bahramzadeh Y and Shahinpoor M (2011) Dynamic curvature sensing employing ionic polymer metal composite sensors. Smart Materials and Structures 20(9): 094011.

Bao XQ, Bar-Cohen Y and Lih SS (2002) Measurement and macro models of ionomeric polymer metal composites (IPMC). In: Proceedings of the SPIE smart structures and materials symposium, EAPAD conference, San Diego, CA, 17 March.

Bar-Cohen Y (2004) Electroactive Polymer (EAP) Actuator as Artificial Muscle: Reality, Potential, and Challenges. Bellingham, WA: SPIE.

Bar-Cohen Y, Leary S, Shahinpoor M, et al. (1999) Flexible low-mass device and mechanisms actuated by electroactive polymers. In: Proceedings of SPIE conference electroactive polymer actuators and devices, Newport Beach, CA, 1 March.

Barramba J, Silva J and Branco PJC (2007) Evaluation of dielectric gel coating for encapsulation of ionic polymermetal composite (IPMC) actuators. Sensors and Actuators A: Physical 140(2): 232-238.

Bennett M (2004) Ionic liquids as stable solvents for ionic polymer transducers. Sensors and Actuators A: Physical 115(1): 79-90.

Bhandari B, Lee G and Ahn SH (2012) A review on IPMC materials as actuators and sensors: fabrications, characteristics and applications. International Journal of Precision Engineering and Manufacturing 13(1): 141-163.

Bonomo C, Brunetto P, Fortuna L, et al. (2008) A tactile sensor for biomedical applications based on IPMCs. IEEE Sensors Journal 8(8): 1486-1493.

Branco PJC and Dente JA (2006) Derivation of a continuum model and its electric equivalent-circuit representation for ionic polymer-metal composite (IPMC) electromechanics. Smart Materials and Structures 15(2): 378-392.

Branco PJC, Lopes B and Dente JA (2012) Non-uniformly charged ionic polymer-metal composite actuators: electromechanical modeling and experimental validation. IEEE Transactions on Industrial Electronics 59(2): 1105-1113.

Brunetto P, Fortuna L, Giannone P, et al. (2010) A resonant vibrating tactile probe for biomedical applications based on IPMC. IEEE Transactions on Instrumentation and Measurement 59(5): 1453-1462.

Brunetto P, Fortuna L, Giannone P, et al. (2011) Characterization of the temperature and humidity influence on ionic polymer-metal composites as sensors. IEEE Transactions on Instrumentation and Measurement 60(8): 2951-2959.

Cha Y and Porfiri M (2013) Bias-dependent model of the electrical impendence of ionic polymer-metal composites. Physical Review E: Statistical, Nonlinear, and Soft Matter Physics 87(2): 022403.

Cha Y, Aureli M and Porfiri M (2012) A physics-based model of the electrical impendence of ionic polymer metal composites. Journal of Applied Physics 111(12): 124901-1124901-14.

Chen XF, Zhu GM, Yang XJ, et al. (2013) Model-based estimation of flow characteristics using an ionic polymermetal composite beam. IEEE/ASME Transactions on Mechatronics 18(3): 932-943. 
Chen Z and Tan XB (2008) A control-oriented and physicsbased model for ionic polymer metal composite actuator. IEEE/ASME Transactions on Mechatronics 13(5): 519529.

Chen Z, Hedgepeth DR and Tan XB (2009) A nonlinear, control-oriented model for ionic polymer-metal composite actuators. Smart Materials and Structures 18(5): 055008.

Chen Z, Shatara S and Tan XB (2010) Modeling of biomimetic robotic fish propelled by an ionic polymer-metal composite caudal fin. IEEE/ASME Transactions on Mechatronics 15(3): 448-459.

Chen Z, Tan XB, Will A, et al. (2007) A dynamic model for ionic polymer metal composite sensors. Smart Materials and Structures 16(4): 1477-1488.

Colozza A (2007) Fly like a bird. IEEE Spectrum 44(5): 38-43.

Darryll JP (2005) Proposer Information Pamphlet (PI) for Defense Advanced Research Project Agency (DARPA) Defense Sciences Office (DSO) Nano Air Vehicle (NAV) Program. Technical report 06-06, 25 October. Arlington, VA: DARPA DSO.

De Gennes PG, Okumura K, Shahinpoor M, et al. (2000) Mechanoelectric effects in ionic gels. Europhysics Letters 50(4): 513-518.

Del Bufalo G, Placidi L and Porfiri M (2008) A mixture theory framework for modelling the mechanical actuation of ionic polymer metal composites. Smart Materials and Structures 17(4): 045010.

Fang B, Ju M and Lin C (2007) A new approach to develop ionic polymer-metal composite actuators. Sensors and Actuators A: Physical 137: 321-329.

Farinholt K and Leo D (2004) Modeling of electromechanical charge sensing in ionic polymer transducers. Mechanics of Materials 36(5): 421-433.

Fotsing YK and Tan XB (2012) Bias-dependent impedance model for ionic polymer-metal composites. Journal of Applied Physics 111(12): 124907.

Galante S, Lucantonio A and Nardinocchi P (2013) The multiplicative decomposition of the deformation gradient in the multiphysics modeling of ionic polymers. International Journal of Non-linear Mechanics 51: 112-120.

Jung JH, Jeon JH, Sridhar V, et al. (2011) Electro-active graphene-Nafion actuators. Carbon 49(4): 1279-1289.

Jung K, Nam J and Choi H (2003) Investigation on actuation characteristics of IPMC artificial muscle actuator. Sensors and Actuators A: Physical 107(2): 183-192.

Kanno R, Kurata A, Hattori M, et al. (1994) Characteristics and modeling of ICPF actuator. In: Proceedings of the Japan-USA symposium on flexible automation, vol. 2, pp. 691-698, kobe, Japan, 11, July.

Kim HI, Kim DK and Han JH (2007) Study of flapping actuator modules using IPMC. In: Proceedings of SPIE 6524, electroactive polymer actuators and devices (EAPAD), paper no. 65241A, San Diego, CA, 18 March.

Kim KJ, Pugal D and Leang KK (2011a) A twistable ionic polymer-metal composites artificial muscle for marine application. Marine Technology Society Journal 45(4): 83-98.

Kim SM, Tiwari R and Kim KJ (2011b) A novel ionic polymer metal ZnO composite (IPMZC). Sensors 11(5): 4674 4687.

Lee GY, Choi JO, Kim M, et al. (2011a) Fabrication and reliable implementation of an ionic polymer metal composite
(IPMC) biaxial bending actuator. Smart Materials and Structures 20(10): 105026.

Lee JH, Oh JS, Jeong GH, et al. (2011b) New computational model for predicting the mechanical behaviour of ionic polymer metal composite (IPMC) actuators. International Journal of Precision Engineering and Manufacturing 12(4): 737-740

Lee SG, Park HC, Pandita SD, et al. (2006) Performance improvement of IPMC for a flapping actuator. International Journal of Control, Automation and Systems 4(6): 748-755.

Lin HH, Fang BK, Ju MS, et al. (2009) Control of ionic polymer-metal composites for active catheter systems via linear parameter-varying approach. Journal of Intelligent Material Systems and Structures 20(3): 273-282.

Liu Z, Xu M, Moschetta JM, et al. (2010) A review on conceptual design of nano air vehicles. Chinese Science Bulletin 55(34): 3257-3268.

Madden JDW, Vandesteeg NA, Anquetil PA, et al. (2004) Artificial muscle technology: physical principles and naval prospects. IEEE Journal of Oceanic Engineering 29(3): 706-728

Najem J, Sarles SA, Akle B, et al. (2012) Biomimetic jellyfishinspired underwater vehicle actuated by ionic polymer metal composite actuators. Smart Materials and Structures 21(9): 094026.

Nardinocchi P, Pezzulla M and Placidi L (2011) Thermodynamically based multiphysic modeling of ionic polymer metal composites. Journal of Intelligent Material Systems and Structures 22(16): 1887-1897.

Nemat-Nasser S and Wu YX (2003) Comparative experimental study of ionic polymer-metal composites with different backbone ionomers and in various cation forms. Journal of Applied Physics 93(9): 5255-5267.

Nemat-Nasser S and Zamani S (2003) Experimental study of Nafion-and Flemion-based ionic polymer metal composites (IPMCs) with ethylene glycol as solvent. In: Proceedings of SPIE conference smart structures and materials 2003: electroactive polymer actuators and devices ( $E A P A D)$, San Diego, CA, 2 March.

Newbury KM and Leo DJ (2003) Linear electromechanical model of ionic polymer transducers. Part I: model development. Journal of Intelligent Material Systems and Structures 14(6): 333-342.

O'Halloran A, O'Malley F and McHugh P (2008) A review on dielectric actuators, technology, application, and challenges. Journal of Applied Physics 104(7): 071101.

Porfiri M (2008) Charge dynamic in ionic polymer metal composites. Journal of Applied Physics 104(10): 104915-1104915-10.

Porfiri M (2009a) An electromechanical model for sensing and actuation of ionic polymer metal composites. Smart Materials and Structures 18(1): 015016.

Porfiri M (2009b) Influence of electrode surface roughness and steric effects on the nonlinear electromechanical behaviour of ionic polymer metal composites. Physical Review E: Statistical, Nonlinear, and Soft Matter Physics 79(4): 041503.

Pugal D, Jung K, Aabloo A, et al. (2010) Ionic polymer metal composites mechanoelectrical transduction: review and perspectives. Polymer International 59: 279-289. 
Rodrigues JL, Almeida RA, Dente JA, et al. (2011) Review of recent patents with applications of ionic polymer-metal composites (IPMCs). Recent Patents on Electrical Engineering 4(1): 10-15.

Shahinpoor M (2003) Ionic polymer-conductor composites as biomimetic sensors, robotic actuators and artificial muscles - a review. Electrochimica Acta 48(14-16): 2343 4353.

Shahinpoor M and Kim KJ (2001) Ionic polymer metal composites: I. Fundamentals. Smart Materials and Structures 10(4): 819-833.

Shahinpoor M and Kim KJ (2004) Ionic polymer metal composites: III. Modeling and simulation as biomimetic sensors, actuators, transducers, and artificial muscles. Smart Materials and Structures 13(6): 1362-1388.

Shahinpoor M and Kim KJ (2005) Ionic polymer-metal composites: IV. Industrial and medical applications. Smart Materials and Structures 14(1): 197-214.

Shahinpoor M, Bar-Cohen Y, Simpson JO, et al. (1998) Ionic polymer metal composites (IPMCs) as biomimetic sensors, actuators and artificial muscles - a review. Smart Materials and Structures 7(6): 15-30.

Tang BR (2003) Probe into application of three parameter method. Journal of Wuhan University of Technology: Materials Science Edition 25(9): 81-84.

Timoshenko S (1953) History of Strength of Materials. New York: McGraw-Hill.

Tiwari R and Kim KJ (2013) IPMC as a mechanoelectric energy harvester: tailored properties. Smart Materials and Structures 22(1): 015017.

Truong DQ, Ahnl KK, Nam DNC, et al. (2010) Identification of a nonlinear black-box model for a self-sensing polymer metal composites actuator. Smart Materials and Structures 19(8): 085015.
Vahabi M, Mehdizadeh E, Kabganian M, et al. (2011) Experimental identification of IPMC actuator parameters through incorporation of linear and nonlinear least square methods. Sensors and Actuators A: Physical 168(1): 140 148.

Wallmersperger T, Leo DJ and Kothera CS (2007) Transport modelling in ionomeric polymer transducers and its relationship to electromechanical coupling. Journal of Applied Physics 101(2): 024912.

Xiao Y and Bhattacharya K (2001) Modeling electromechanical properties of ionic polymers. Smart Materials and Structures 4329: 292-300.

Yeom SW and Oh IK (2009) A biomimetic jellyfish robot based on ionic polymer metal composite actuators. Smart Materials and Structures 18(8): 085002.

Yim W, Trabia MB, Renno JM, et al. (2006) Dynamic modeling of segmented ionic polymer metal composite (IPMC) actuator. In: Proceedings of 2006 IEEE/RSJ international conference of intelligent robots and system, Beijing, China, $9-15$ October.

Yun GY, Kim HS and Kim J (2008) Blocked force measurement of an electro-active paper actuator using a cantilevered force transducer. Smart Materials and Structures 17(2): 025021.

Yun S, Kim J and Song C (2007) Performance of electroactive paper actuators with thickness variation. Sensors and Actuators A: Physical 133(1): 225-230.

Zangrilli U and Weiland LM (2011) Prediction of the ionic polymer transducer sensing of shear loading. Smart Materials and Structures 20(9): 094013.

Zhang W, Guo SX and Liu B (2006) A new type of hybrid fish-like micro-robot. International Journal of Automation and Computing 3(4): 358-365. 